Advocacy for carbon capture and storage could arouse distrust

In addition to industry voices such as Gert Jan Kramer and Martin Haigh (Nature 462, 568-569; 2009), many academic experts are promoting $\mathrm{CO}_{2}$ capture and storage (CCS). But advocacy by academics could be ill-advised.

The technology has significant shortcomings that must be recognized in order to sustain progress. Academics' valuable time would be better spent on research into these limitations, rather than on advocacy. CCS has plenty of powerful supporters in politics and in industry.

A critical expert community must be monitor the development of CCS, to avoid fuelling the kind of controversy that happened over nuclear energy. The lay public needs reliable information on risks and benefits.

Social science indicates that people are more likely to trust independent experts than private-sector or government representatives. But the public will not trust advice from supposedly 'independent' CCS experts who are biased in favour of the technology. This has become obvious through recently stalled CCS projects in the United States, Germany and the Netherlands.

Heleen de Coninck Energy Research Centre of the Netherlands, Radarweg 60, 1043 NT Amsterdam, The Netherlands e-mail:deconinck@ecn.nl

See also Editorial, page 269.

\section{Activists should be consulted in animal testing decisions}

You argue, in an Editorial discussing a university's decision to cancel a primate-research project (Nature 462, 699; 2009), that such decisions should be guided by consultation between administrators, researchers and members of university communities. I contend that it should be extended to include animal-rights activists.

Although such consultations would not necessarily lead to consensus, they could result in learning and transformation on both sides. It is unlikely that animal-rights activists believe that no research on any organism is ever justified. We should therefore try to understand what motivates their deepest concerns - possible examples being the use of primates in testing, the treatment of test animals, the killing of animal subjects or the questionable value of testing.

Attacks are activists' way of forcing themselves into the conversation. Mutual deliberation over possible ways forward could enable universities to make the informed, rather than arbitrary, animal-research decisions that the Editorial is asking for.

Fern Wickson GenØk Centre for Biosafety, Forskningsparken in Breivika, PO Box 6418, 9294 Tromsø, Norway

e-mail: fern.wickson@uit.no

\section{Conservation work is} incomplete without cryptic biodiversity

You focus attention on biological diversity, nature conservation and the effects of climate warming in your special issue on biodiversity (19 November 2009). 'Cryptic' biodiversity is also crucial, because it helps natural ecosystems to continue functioning and habitats to bounce back in response to environmental change.

Cryptic biodiversity includes aquatic organisms invisible to the naked eye, dormant species, and other species present in such low numbers that they go undetected. These are not included in conservation surveys.

Work on cryptic biodiversity has started in the United Kingdom with financial support from the
Esmée Fairbairn Foundation. The project is a partnership among academics and local and national conservation organizations (Dorset Wildlife Trust and Pond Conservation) to link research with conservation. Our aim is to incorporate small aquatic organisms into biodiversity surveys and develop guidelines for the management of cryptic diversity.

Local biodiversity conservation will eventually cover the full range of aquatic organisms - not just the more obviously appealing ones - that contribute to the functioning of a healthy ecosystem and to water quality.

Genoveva F. Esteban, Bland J. Finlay Queen Mary University of London, School of Biological and Chemical Sciences, The River Laboratory, Wareham, Dorset BH20 6BB, UK e-mail:g.esteban@qmul.ac.uk

\section{Geothermal energy stuck between a rock and a hot place}

In his Opinion article, Domenico Giardini (Nature 462, 848-849;

2009) calls for a better understanding of earthquake risk in pursuing deep geothermal energy using an enhanced geothermal system (EGS). However, earthquakes are only part of the problem in trying to tap Earth's internal heat as an alternative clean-energy source. Poorly understood geology is a bigger obstacle.

Geological anomalies halted an EGS demonstration project in Geysers, north California, sponsored by the US Department of Energy. After months of drilling last year, the California-based company AltaRock Energy was unable to penetrate the formation capping the hot rocks that it was targeting $4 \mathrm{~km}$ below the surface. Similar frustrations were encountered during EGS drilling projects at Paralana and the Cooper Basin, both in South Australia.

Depths of 3-10 km are optimal for geothermal exploitation because they are extremely hot and accessible to modern drilling techniques. But even the most carefully planned scientific drilling operations can be victims of geological surprise. For example, scientists at the German Continental Deep Drilling Programme site east of Nuremburg predicted a change in rock type at a depth of about $7 \mathrm{~km}$, corresponding to the boundary between two tectonic plates that collided 320 million years ago. But no such boundary was evident, even after drilling to more than 9 km (B. Yardley Nature 389, 792-793; 1997).

The United States and China are together injecting US\$150 million over the next 5 years into a joint Clean Energy Research Center. Meanwhile, China is launching its ambitious Deep Exploration Technology and Experimentation project, SinoProbe, to locate mineral resources and to find out more about earthquakes and volcanism (S. Dong and T. Li Acta Geologica Sinica 83, 895909; 2009). Together, these ventures should improve our geological understanding and enable us to find drilling sites that are less prone to triggering earthquakes.

Shaopeng Huang Department of Geological Sciences, University of Michigan, Ann Arbor, Michigan 481091005, USA; and State Key Laboratory of Loess and Quaternary Geology, Institute of Earth Environment, Chinese Academy of Sciences, Xian 710075, China e-mail:shaopeng@umich.edu Jiaqi Liu Institute of Geology and Geophysics, Chinese Academy of Sciences, Beijing 100029, China
Correction
While J. P. Albars' Correspondence 'Spanish cuts could do lasting damage to biomedical research' (Nature 463, 157; 2010) was in press, the prospects described in it changed for the better. The Spanish government's department of science and innovation is to be put in charge of the institutions mentioned, so the concerns expressed no longer apply. 